\title{
Reconditioning of lungs donated after circulatory death with normothermic ex vivo lung perfusion.
}

\section{$\operatorname{AUTHOR(S):~}$}

Nakajima, Daisuke; Chen, Fengshi; Yamada, Tetsu; Sakamoto, Jin; Ohsumi, Akihiro; Bando, Toru; Date, Hiroshi

\section{CITATION:}

Nakajima, Daisuke ... [et al]. Reconditioning of lungs donated after circulatory death with normothermic ex vivo lung perfusion.. The Journal of heart and lung transplantation : the official publication of the International Society for Heart Transplantation 2012, 31(2): 187-193

\section{ISSUE DATE:}

2012-02

URL:

http://hdl.handle.net/2433/153983

\section{RIGHT:}

(C) 2012 International Society for Heart and Lung Transplantation. Published by Elsevier Inc.; この論文は出版社版でありません。引用の際には出版社版をご確認ご利用ください 。; This is not the published version. Please cite only the published version. 
The title: Reconditioning of The Lungs Donated after Circulatory Death with Normothermic Ex Vivo Lung Perfusion

Authors: Daisuke Nakajima, MD a, Fengshi Chen, MD a, Tetsu Yamada, MD a, Jin Sakamoto, MD a , Akihiro Ohsumi, MD a, Toru Bando, MD a, Hiroshi Date, MD a

a Department of Thoracic Surgery, Graduate School of Medicine, Kyoto University, Kyoto, Japan

Key words: ex vivo lung perfusion, DCD, ischemia reperfusion injury, lung transplantation

Word count: abstract 247 words, text 2999 words

Part of this work was presented at the International Society for Heart and Lung Transplantation 31st Annual Meeting and Scientific Sessions, April 13-16, 2011, San Diego, California

\section{Address for correspondence:}

Corresponding author: Hiroshi Date

54 Shogoin Kawahara-cho, Sakyo-ku, Kyoto, Japan

+81-75-751-4975 (business), +81-75-468-8979 (home)

Fax number: +81-75-751-4974 (business), +81-75-468-8979 (home)

hdate@kuhp.kyoto-u.ac.jp 


\section{Abstract}

Background. The use of donation after circulatory death (DCD) donors for lung transplantation has come into practice. This study investigated whether DCD lungs can be resuscitated after warm ischemia with normothermic ex vivo lung perfusion (EVLP).

Methods. Four hours after cardiac arrest, beagles were divided into 2 groups (n=6 each): those with static cold storage (SCS group) or normothermic EVLP (EVLP group) for $3.5 \mathrm{~h}$. The physiological lung functions were evaluated during EVLP. In both groups, the left lungs were then transplanted and reperfused for $4 \mathrm{~h}$ to evaluate the posttransplant lung functions. The lung tissue adenosine triphosphate (ATP) levels were measured at given time points.

Results. Lung oxygenation was significantly improved with EVLP ( $p<0.01$ ), and lung oxygenation at the end of EVLP significantly reflected the posttransplant lung oxygenation $(\mathrm{r}=0.99, \mathrm{p}<0.01)$. The posttransplant lung oxygenation was significantly better in the EVLP group compared with the SCS group $(p<0.05)$. The dynamic pulmonary compliance and wet to dry lung weight ratio $4 \mathrm{~h}$ after transplantation were also significantly better in the EVLP group than in the SCS group $(\mathrm{p}<0.05)$. Microthrombi in the donor lungs before transplantation were microscopically detected more often in the SCS group. The lung tissue ATP levels 4 $\mathrm{h}$ after transplantation were significantly higher in the EVLP group compared with the SCS group $(\mathrm{p}=0.03)$.

Conclusions. Normothermic ex vivo lung perfusion could resuscitate DCD lungs injured by warm ischemia, and might ameliorate ischemia reperfusion injury. 


\section{Introduction}

There has been a progressive increase in the number of patients on the waiting list, which continually exceeds the number of available organs. The use of DCD donors has been employed to resolve this problem (1-5). Severe warm ischemia reperfusion injury may lead to primary graft dysfunction, and remains a significant cause of early morbidity and mortality after lung transplantation $(6,7)$. The inhibition of warm ischemia reperfusion injury is, therefore, crucial to facilitate lung transplantation from DCD donors.

The principle of EVLP is to recreate the physiological environment by maintaining normothermia and providing the essential substrates for cellular metabolism. Therefore, EVLP enables organ viability assessment, prolonged preservation, and resuscitation from injuries before transplantation. Steen and colleagues developed an ex vivo system for evaluating the functions of DCD lungs before transplantation, and successfully performed lung transplantation from an uncontrolled DCD donor in 2000 (8). Cypel and colleagues established a successful prolonged EVLP system (9). EVLP can also provide access for the administration of cytoprotective and immunomodulatory drugs, and can allow for both the pretreatment and reconditioning of marginal donor lungs (10).

We simulated a clinically relevant uncontrolled DCD model in the current study. We have previously reported the protective effects of nitroglycerin (NTG) and dibutyryl cyclic adenosine monophosphate (db-cAMP) for ischemia reperfusion injury (11-13). In this study, we investigated whether EVLP using the STEEN solution with NTG and db-cAMP would resuscitate DCD lungs after warm ischemia, 
and would ameliorate ischemia reperfusion injury.

\section{Materials and Methods}

\section{Animals}

Beagles weighting from 9 to $15 \mathrm{~kg}$ (Kitayama Labes Co. Ltd., Hongo Farm, Yamaguchi, Japan) were used in this study. All animals received humane care in compliance with the Principals of Laboratory Animal Care, formulated by the United States National Society for Medical Research, and the Guide for the Care and Use of Laboratory Animals, prepared by the US Institute of Laboratory Animal Resources and published by the National Institutes of Health (NIH Publication 85-23, revised 1996). The study was approved by the Ethics Committee of the Faculty of Medicine at Kyoto University, Japan.

\section{Study design}

The beagles were anesthetized with an intramuscular injection of midazolam (0.5 $\mathrm{mg} / \mathrm{kg})$, xylazine $(0.25 \mathrm{mg} / \mathrm{kg})$, and atropine sulfate $(0.05 \mathrm{mg} / \mathrm{kg})$. The animals were intubated and ventilated with an inspired oxygen fraction $\left(\mathrm{FiO}_{2}\right)$ of 1.0 , a tidal volume of $25 \mathrm{ml} / \mathrm{kg}$, a frequency of 15 breaths/min, and a positive end-expiratory pressure (PEEP) of $5 \mathrm{cmH}_{2} \mathrm{O}$. Cardiac arrest was induced by the intravenous injection of potassium chloride $(0.5 \mathrm{mEq} / \mathrm{kg})$ without heparinization. The chest was opened before cardiac arrest to collect the lung tissue biopsies and was kept open during $4 \mathrm{~h}$ of warm ischemia. The tracheal tube was disconnected from the ventilator and left open to the air after cardiac arrest. Therefore, the donor lungs kept collapsed completely during $4 \mathrm{~h}$ of warm ischemia. Four hours after cardiac 
arrest, the mechanical ventilation was resumed as described above, the main pulmonary artery was cannulated, the superior and inferior vena cava were tied, and the left atrial appendage was incised. Antegrade and retrograde flushes of the lungs were performed with $1,000 \mathrm{ml}$ and $500 \mathrm{ml}$ of ET-Kyoto solution (Otsuka Pharmaceutical Factory Inc, Tokushima, Japan), respectively. After the donor lungs were retrieved, they were divided into 2 groups ( $n=6$ each): static cold storage with ET-Kyoto solution at $4^{\circ} \mathrm{C}$ for $3.5 \mathrm{~h}$ (SCS group) or normothermic EVLP for $3.5 \mathrm{~h}$ (EVLP group). In both groups, the left lung was then transplanted to a recipient. The bronchial anastomosis was performed first with a running 5-0 PDS suture, the left atrial anastomosis was performed next with a running 6-0 prolene suture, and then the pulmonary arterial anastomosis was performed with a running 6-0 prolene suture. The implantation time was set for $60 \mathrm{~min}$. After the transplanted lung was reinflated and mechanically ventilated as described above, the PA clamp was gradually removed and the transplanted lung was reperfused for $4 \mathrm{~h}$ to evaluate the posttransplant lung functions. The right pulmonary artery was occluded with a tourniquet at $45 \mathrm{~min}$ of reperfusion to specifically evaluate the functions of the transplanted lung.

\section{Ex vivo lung perfusion (EVLP)}

EVLP was performed as described by Cypel and colleagues (14). The lungs were placed in the XVIVO chamber (Vitrolife, Denver, CO). The trachea was intubated and connected to the ventilator. The pulmonary artery and left atrial appendage were cannulated directly and connected to the perfusion circuit. The EVLP perfusate consisted of STEEN solution (1,500 ml) with methylprednisolone (500 mg), 
heparin (10,000 IU), cefazolin (500 mg), db-cAMP (1,500 mg), and NTG (75 mg). The perfusate was driven by a centrifugal pump at a constant flow rate. The perfusate flow was initiated at $10 \%$ of the full flow rate at room temperature. The temperature of the perfusate was gradually increased to $37^{\circ} \mathrm{C}$. When the temperature of the perfusate reached $32^{\circ} \mathrm{C}$, ventilation was started with a $\mathrm{FiO}_{2}$ of 0.21 , tidal volume of $10 \mathrm{ml} / \mathrm{kg}$, frequency of $10 \mathrm{breaths} / \mathrm{min}$ and $\mathrm{PEEP}$ of $5 \mathrm{cmH}_{2} \mathrm{O}$, and the deoxygenation of the perfusate from the lungs was started with a gas mixture of nitrogen (86\%), carbon dioxide (8\%), and oxygen $(6 \%)$. The perfusate flow rate was gradually increased to the full flow rate which was $40 \%$ of estimated cardiac output $(\mathrm{CO}=100 \mathrm{ml} / \mathrm{kg})$. EVLP at the full flow rate was conducted for 90 min. The time point at which the perfusion flow reached the full flow rate was defined as the base line (BL), and the physiological lung functions during EVLP were evaluated every $30 \mathrm{~min}$. The pulmonary arterial pressure, left atrial pressure, and peak airway pressure were all continuously monitored, and the left atrial pressure was maintained at 3 to $5 \mathrm{mmHg}$ throughout the experiments. Dynamic pulmonary compliance was defined as tidal volume/(PawP-PEEP) $\left(\mathrm{ml} / \mathrm{cmH}_{2} \mathrm{O}\right)$. A blood gas analysis of the perfusate to and from the lungs was performed every 30 min after 10 min exposure to $\mathrm{FiO}_{2}$ of 1.0 . The temperature of the perfusate was cooled down to $20^{\circ} \mathrm{C}$ after the last evaluation, and then perfusion and ventilation were stopped. The donor lungs semiinflated with air were then stored in ET-Kyoto solution at $4{ }^{\circ} \mathrm{C}$ until transplantation.

\section{Posttransplant lung functions}

The pulmonary arterial pressure and peak airway pressure were continuously 
monitored throughout the experiments. Dynamic pulmonary compliance was defined as described above. A blood gas analysis was performed from the femoral artery and pulmonary artery at given time points. Lung tissue biopsy samples collected from the left lower lobe $4 \mathrm{~h}$ after transplantation were weighed as the wet lung weight, placed in an oven at $180^{\circ} \mathrm{C}$ for $24 \mathrm{~h}$, and then reweighed as the dry lung weight. The wet to dry lung weight ratio was calculated to evaluate the presence of lung edema.

\section{Histological evaluation of microthrombi before transplantation and ischemia reperfusion injury}

Lung tissue biopsies were collected from the right upper lobe before transplantation and the left upper lobe $4 \mathrm{~h}$ after transplantation to microscopically evaluate the formation of microthrombi in the donor lungs before transplantation and ischemia reperfusion injury after transplantation. They were fixed in $10 \%$ buffered formalin, embedded in paraffin, and stained with hematoxylin and eosin. Ischemia reperfusion injury was scored blindly by two investigators (D.N. and J.S.) using a four-point scale according to the combined assessment of edema (interstitial and intra-alveolar congestion), hemorrhage, inflammatory cell infiltration, and hyaline membrane formation: $0=$ absent, $1=$ mild, $2=$ moderate, $3=$ severe damage $(15,16)$.

\section{Lung tissue energy levels}

Lung tissue biopsies were collected from the right lower lobe before cardiac arrest and after warm ischemia, and then were collected from the left lower lobe $4 \mathrm{~h}$ after transplantation. The levels of adenosine triphosphate (ATP) were measured by 
high-performance liquid chromatography using a Shim-pack CLC-ODS column (15 $\mathrm{cm} \times 6.0 \mathrm{~mm}$; Shimadzu, Japan) and $100 \mathrm{mM}$ sodium phosphate buffer (PH 6.0) at a wavelength of $260 \mathrm{~nm}$, as previously described (17).

\section{Statistical analysis}

All data are presented as the means \pm standard deviation. The statistical analysis was performed by Student's $t$-test, the Mann-Whitney U test, and the $\chi^{2}$ test. A p value less than 0.05 was considered to be statistically significant.

\section{Results}

\section{Physiological lung functions}

One beagle died due to severe pulmonary edema $2.5 \mathrm{~h}$ after transplantation in each group. These two animals were excluded from the data analysis $3 \mathrm{~h}$ and $4 \mathrm{~h}$ after transplantation.

Lung oxygenation was significantly improved by EVLP ( $<<0.01$; Figure 1A). In detail, the $\mathrm{PaO}_{2}$ at the baseline of EVLP and the end of EVLP were $437 \pm 68$ $\mathrm{mmHg}$ and $558 \pm 35 \mathrm{mmHg}$, respectively. The dynamic pulmonary compliance and pulmonary vascular resistance were stable during EVLP (Figures 1B and C).

The posttransplant lung oxygenation was significantly better in the EVLP group than that in the SCS group $3 \mathrm{~h}$ and $4 \mathrm{~h}$ after transplantation $(\mathrm{p}<0.05$; Figure 2A). The dynamic pulmonary compliance $4 \mathrm{~h}$ after transplantation was significantly better in the EVLP group than that in the SCS group (EVLP group $13.02 \pm 0.99$ $\mathrm{ml} / \mathrm{cmH}_{2} \mathrm{O}$, SCS group $11.26 \pm 0.99 \mathrm{ml} / \mathrm{cmH}_{2} \mathrm{O} ; \mathrm{p}<0.05$; Figure $\left.2 \mathrm{~B}\right)$. The wet to dry lung weight ratio $4 \mathrm{~h}$ after transplantation was also significantly lower in the 
EVLP group than that in the SCS group (EVLP group $6.30 \pm 0.54$, SCS group $10.92 \pm 0.86 ; p<0.01 ;$ Figure 2C).

The lung oxygenation at the end of EVLP was significantly correlated with the lung oxygenation $4 \mathrm{~h}$ after transplantation $(\mathrm{r}=0.99, \mathrm{p}<0.01$; Figure $3 \mathrm{~A})$. However, there was no significant correlation between the dynamic pulmonary compliance at the end of EVLP and that $4 \mathrm{~h}$ after transplantation $(\mathrm{r}=0.55, \mathrm{p}=0.33$; Figure $3 \mathrm{~B})$.

\section{Histological findings of ischemia reperfusion injury}

Severe interstitial and intra-alveolar edema, hemorrhage, infiltration or aggregation of inflammatory cells in the air space or vessel wall, and hyaline formation were detected in the SCS group $4 \mathrm{~h}$ after transplantation (Figures $4 \mathrm{~A}$ and B). The acute lung injury score was significantly lower in the EVLP group compared with the SCS group (EVLP group: $24.5 \pm 3.1$, SCS group: $32.3 \pm 6.4, \mathrm{p}=0.03$; Figure 4C).

\section{The formation of microthrombi before transplantation}

In the macroscopic findings, the surface of donor lungs looked uniformly perfused 90 min after EVLP (Figures 5A and B). In the donor lungs before transplantation, residual blood cells or blood clots were microscopically observed more often in the SCS group compared with the EVLP group (Figures 6A and B).

\section{Lung tissue energy level}

In the EVLP group, the lung tissue ATP levels which decreased during warm ischemia were improved to the normal levels observed before cardiac arrest $4 \mathrm{~h}$ 
after transplantation (Figure 7). The lung tissue ATP levels $4 \mathrm{~h}$ after transplantation were significantly higher in the EVLP group compared with the SCS group $(p=0.03$; Figure 7). The ATP levels before cardiac arrest and after warm ischemia were $3.27 \pm 0.37$ and $1.67 \pm 0.55 \mathrm{nmol} / \mathrm{mg}$, respectively. The ATP levels $4 \mathrm{~h}$ after transplantation in the EVLP group and in the SCS group were $3.27 \pm 0.54$, and $2.37 \pm 0.49 \mathrm{nmol} / \mathrm{mg}$, respectively.

\section{Discussion}

This study demonstrated that normothermic EVLP with db-cAMP and NTG could resuscitate DCD lungs injured by $4 \mathrm{~h}$ of warm ischemia, and could ameliorate ischemia reperfusion injury compared with static cold storage. Cypel and colleagues have established a successful prolonged EVLP system using an acellular perfusate, and suggested that this system can be used to assess, maintain, and treat injured donor lungs (14). We also have adapted their technique, and confirmed excellent lung performance during $8 \mathrm{~h}$ of EVLP (unpublished data). The current study found that the lung oxygenation at the end of EVLP was significantly correlated with the lung oxygenation after transplantation, and thus our EVLP system can be useful to evaluate the oxygenation of DCD lungs before transplantation. Cypel and colleagues recently demonstrated in their clinical study that lung transplantation using high risk donor lungs that are stable physiologically during $4 \mathrm{~h}$ of EVLP led to results similar to conventional lung transplantation (18). In their study, lung oxygenation in high risk donor lungs was improved 1-2 $\mathrm{h}$ after EVLP. Steen and colleagues demonstrated that EVLP could be used for reconditioning of initially rejected donor lungs, and the median reconditioning time was 1 hour and 29 
minutes (19). Therefore, in the current study, EVLP at a full flow rate was conducted for 1 hour 30 minutes. We found that the lung oxygenation was significantly improved by short-term EVLP, and that the other lung functions were stable during EVLP.

Intravascular pulmonary microthrombus formation, which results in an increase of intrapulmonary shunting, is one of the major causes of reperfusion injury in lung transplantation from DCD donors. The benefits of additional retrograde flush has been shown in experimental and clinical lung transplantation (20-23). In the current study, the donor lungs were macroscopically perfused uniformly by EVLP, although the surface of the donor lungs looked patchy after the antegrade and retrograde flushes. Furthermore, histological examination of the donor lungs before transplantation revealed fewer microthrombi in the EVLP group compared with the SCS group. These results indicated that some residual microthrombi wedged in the precapillary area after the antegrade and retrograde flushes were eliminated by EVLP. As a result, the intrapulmonary shunting in the donor lungs improved, and the lung oxygenation also significantly improved by EVLP.

EVLP can provide access for the administration of cytoprotective drugs, and can perform pretreatment and reconditioning of marginal donor lungs $(24,25)$. In the current study, db-cAMP and NTG were included in the perfusate. A previous study demonstrated that the intracellular cAMP levels were decreased in DCD lungs (17). Db-cAMP elevates the intracellular levels of cAMP, which acts as a second messenger in suppressing vascular permeability, relaxing vascular smooth muscle, and suppressing neutrophil adhesion to the vascular wall (13). On the other 
hand, NTG works in vivo as an NO donor. NO stimulates the production of cGMP, which acts as an intracellular second messenger for relaxing vascular smooth muscle, inhibiting platelet adhesion and aggregation, and adjusting the vascular permeability (12).

Oxidative energy production by mitochondrial electron transport would still be sustained to some extent at hypothermia. Therefore, lung cells are able to maintain aerobic metabolism using the oxygen present in the alveoli during preservation (26). In the SCS group, the lung ATP levels which decreased during warm ischemia were improved, but did not reach the normal levels after transplantation. EVLP washed out the residual microthrombi in the donor lungs, thus resulting in a more uniform distribution of the preservation solution, including nutrition. As a result, ATP synthesis was completely restored in the whole lung cells during normothermic EVLP, and the ATP levels decreased during warm ischemia were improved to the normal levels after transplantation. It might be easier to prove the metabolic benefits of EVLP, if the ATP levels after warm ischemia were compared to those at the end of EVLP. Energy charges maintain the homeostasis and structural competence of the vasculature and parenchymal cell interactions, and marginal donor lungs can maintain their integrity of the structural elements necessary to recover from various injuries.

This study had several limitations. First, although we simulated a clinically relevant uncontrolled DCD model, cardiac arrest was induced by the intravenous injection of potassium chloride. Such an abrupt cardiac arrest might be removed from the clinical reality in that there was not an agonal phase which is an almost invariable component of DCD. Second, EVLP was performed immediately after 
organ retrieval. Clinical practice may require some additional time for donor lungs to be transported from a donor hospital to a transplant center. Thus, EVLP may be effective after static cold storage, just before lung transplantation in a transplant center. Third, the addition of db-cAMP and NTG in the perfusate resulted in an inability to conclusively prove that EVLP alone was responsible for all of the benefits observed in this study. How much these additional additives contributed to the benefits of EVLP would require further study. Finally, one beagle died due to pulmonary edema after transplantation in the EVLP group, as well as in the SCS group. The reason why EVLP could not resuscitate the donor lungs, and could not reduce the ischemia reperfusion injury in the fatal case therefore requires further study.

In conclusion, short-term EVLP washed out residual pulmonary microthrombi, and restored the lung tissue ATP levels which decreased during warm ischemia to the normal levels. As a result, DCD lungs could be resuscitated after warm ischemia, and ischemia reperfusion injury could therefore be ameliorated with short-term EVLP.

\section{Disclosure statement}

The authors have no conflicts of interest to disclose. 


\section{Figure legends}

Figure 1. Physiological lung functions during 90 minutes of EVLP at the full flow rate. $(\mathrm{BL}=$ baseline, $\mathrm{EVLP}=$ ex vivo lung perfusion $) .{ }^{*} \mathrm{p}<0.01$ between the lung oxygenation at the baseline of EVLP and that after 90 min of EVLP.

Figure 2. Physiological lung functions after transplantation. (EVLP $=e x$ vivo lung perfusion, SCS = static cold storage). $(\mathrm{A}) * \mathrm{p}<0.05$ between the EVLP group (boxes) and the SCS group (open circles). (B) $* p<0.05$ and $* * p<0.01$.

Figure 3. The correlation between the physiological lung functions at the end of EVLP and those $4 \mathrm{~h}$ after transplantation. (EVLP $=e x$ vivo lung perfusion). (A) The lung oxygenation at the end of EVLP was significantly correlated with the lung oxygenation $4 \mathrm{~h}$ after transplantation $(\mathrm{r}=0.99, \mathrm{p}<0.01)$. (B) There was no significant correlation between the dynamic pulmonary compliance at the end of EVLP and that $4 \mathrm{~h}$ after transplantation $(\mathrm{r}=0.55, \mathrm{p}=0.33)$

Figure 4. The histological findings of ischemia reperfusion injury in the EVLP group (A) and the SCS group (B). (EVLP = ex vivo lung perfusion, SCS = static cold storage). (C) Ischemia reperfusion injury was scored using a four-point scale according to the combined assessment of edema, hemorrhage, inflammatory cell infiltration, and hyaline membrane formation. ${ }^{*} \mathrm{p}=0.03$.

Figure 5. The macroscopic findings at the baseline of EVLP (A) and after $90 \mathrm{~min}$ of EVLP (B). (EVLP = ex vivo lung perfusion). 
Figure 6. The formation of microthrombi in the donor lungs before transplantation in the EVLP group (A) and the SCS group (B). (EVLP = ex vivo lung perfusion, SCS $=$ static cold storage). The arrows indicate residual intravascular microthrombi.

Figure 7. Lung tissue ATP levels before cardiac arrest, after warm ischemia, and $4 \mathrm{~h}$ after transplantation in each group. ${ }^{*} \mathrm{p}=0.03$. 


\section{References}

1. de Antonio DG, Marcos R, Laporta R, et al. Results of clinical lung transplant

from uncontrolled non-heart-beating donors. J.Heart Lung Transplant.

2007;26(5):529.

2. De Oliveira NC, Osaki S, Maloney JD, et al. Lung transplantation with donation after cardiac death donors: long-term follow-up in a single center.

J.Thorac.Cardiovasc.Surg. 2010;139(5):1306.

3. Erasmus ME, Verschuuren EA, Nijkamp DM, Vermeyden JW, van der Bij W.

Lung transplantation from nonheparinized category III non-heart-beating donors. A single-centre report. Transplantation 2010;89(4):452.

4. Mason DP, Murthy SC, Gonzalez-Stawinski GV, et al. Early experience with lung transplantation using donors after cardiac death. J.Heart Lung Transplant. 2008;27(5):561.

5. Puri V, Scavuzzo M, Guthrie T, et al. Lung transplantation and donation after cardiac death: a single center experience. Ann.Thorac.Surg. 2009;88(5):1609. 
6. Botha P, Trivedi D, Weir CJ, et al. Extended donor criteria in lung

transplantation: impact on organ allocation. J.Thorac.Cardiovasc.Surg.

2006;131(5):1154.

7. de Perrot M, Liu M, Waddell TK, Keshavjee S. Ischemia-reperfusion-induced lung injury. Am.J.Respir.Crit.Care Med. 2003;167(4):490.

8. Steen S, Sjoberg T, Pierre L, Liao Q, Eriksson L, Algotsson L. Transplantation of lungs from a non-heart-beating donor. Lancet 2001;357(9259):825.

9. Cypel M, Rubacha M, Yeung J, et al. Normothermic ex vivo perfusion prevents lung injury compared to extended cold preservation for transplantation.

Am.J.Transplant. 2009;9(10):2262.

10. Reddy SP, Brockmann J, Friend PJ. Normothermic perfusion: a mini-review.

Transplantation 2009;87(5):631.

11. Bando T, Albes JM, Schone J, et al. Significance of cyclic adenosine monophosphate and nitroglycerin in ET-Kyoto solution for lung preservation.

Ann.Thorac.Surg. 2000;69(3):887. 
12. Kawashima M, Bando T, Nakamura T, et al. Cytoprotective effects of nitroglycerin in ischemia-reperfusion-induced lung injury. Am.J.Respir.Crit.Care Med. 2000;161(3 Pt 1):935.

13. Nakamura T, Hirata T, Fukuse T, Ueda M, Hitomi S, Wada H. Dibutyryl cyclic adenosine monophosphate attenuates lung injury caused by cold preservation and ischemia-reperfusion. J.Thorac.Cardiovasc.Surg. 1997;114(4):635.

14. Cypel M, Yeung JC, Hirayama S, et al. Technique for prolonged normothermic ex vivo lung perfusion. J.Heart Lung Transplant. 2008;27(12):1319.

15. Bregeon F, Papazian L, Delpierre S, et al. Role of proinflammatory activity contained in gastric juice from intensive care unit patients to induce lung injury in a rabbit aspiration model. Crit.Care Med. 2008;36(12):3205.

16. Frank JA, Pittet JF, Wray C, Matthay MA. Protection from experimental ventilator-induced acute lung injury by IL-1 receptor blockade. Thorax 2008;63(2):147. 
17. Chen F, Nakamura T, Fujinaga T, et al. Protective effect of a nebulized beta2-adrenoreceptor agonist in warm ischemic-reperfused rat lungs.

Ann.Thorac.Surg. 2006;82(2):465.

18. Cypel M, Yeung JC, Liu M, et al. Normothermic ex vivo lung perfusion in clinical lung transplantation. N.Engl.J.Med. 2011;364(15):1431.

19. Ingemansson R, Eyjolfsson A, Mared L, et al. Clinical transplantation of initially rejected donor lungs after reconditioning ex vivo. Ann.Thorac.Surg. 2009;87(1):255.

20. Hayama M, Date H, Oto T, Aoe M, Andou A, Shimizu N. Improved lung function by means of retrograde flush in canine lung transplantation with non-heart-beating donors. J.Thorac.Cardiovasc.Surg. 2003;125(4):901.

21. Oto T, Rabinov M, Griffiths AP, et al. Unexpected donor pulmonary embolism affects early outcomes after lung transplantation: a major mechanism of primary graft failure? J.Thorac.Cardiovasc.Surg. 2005;130(5):1446.

22. Van De Wauwer C, Neyrinck AP, Geudens N, et al. Retrograde flush following topical cooling is superior to preserve the non-heart-beating donor lung.

Eur.J.Cardiothorac.Surg. 2007;31(6):1125. 
23. Van De Wauwer C, Neyrinck AP, Geudens N, et al. Retrograde flush following warm ischemia in the non-heart-beating donor results in superior graft performance at reperfusion. J.Surg.Res. 2009;154(1):118.

24. Inci I, Ampollini L, Arni S, et al. Ex vivo reconditioning of marginal donor lungs injured by acid aspiration. J.Heart Lung Transplant. 2008;27(11):1229.

25. Dong BM, Abano JB, Egan TM. Nitric oxide ventilation of rat lungs from non-heart-beating donors improves posttransplant function. Am.J.Transplant. 2009;9(12):2707.

26. Date H, Matsumura A, Manchester JK, Cooper JM, Lowry OH, Cooper JD. Changes in alveolar oxygen and carbon dioxide concentration and oxygen consumption during lung preservation. The maintenance of aerobic metabolism during lung preservation. J.Thorac.Cardiovasc.Surg. 1993;105(3):492. 
(1). 京都大学
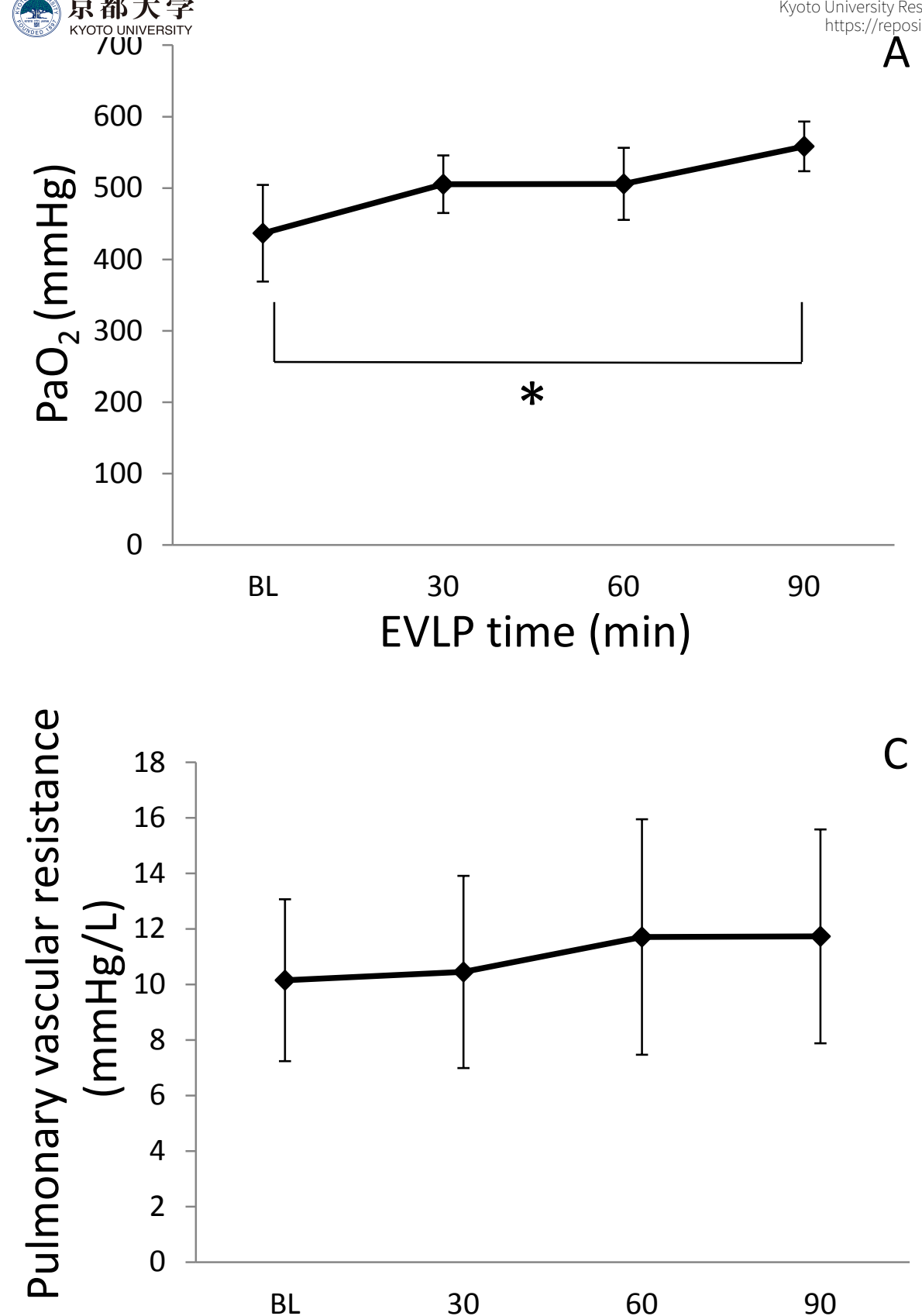

过
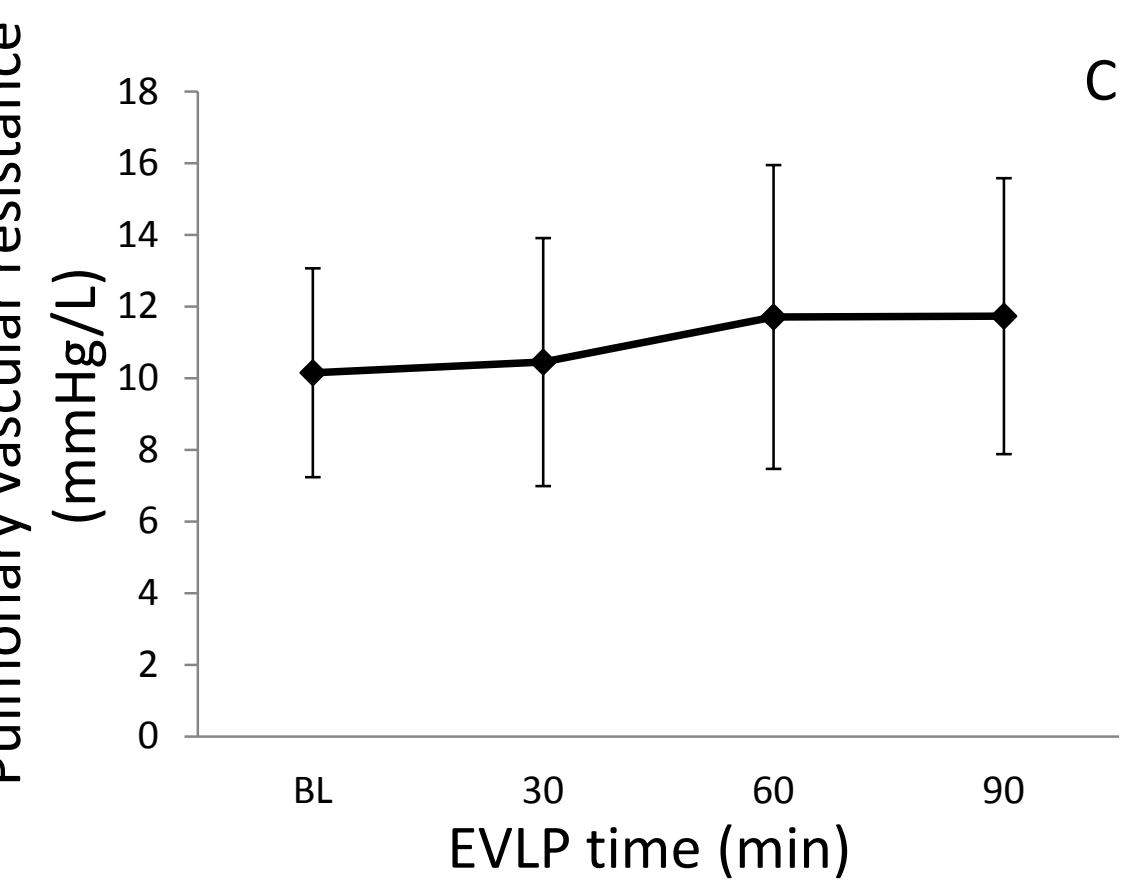

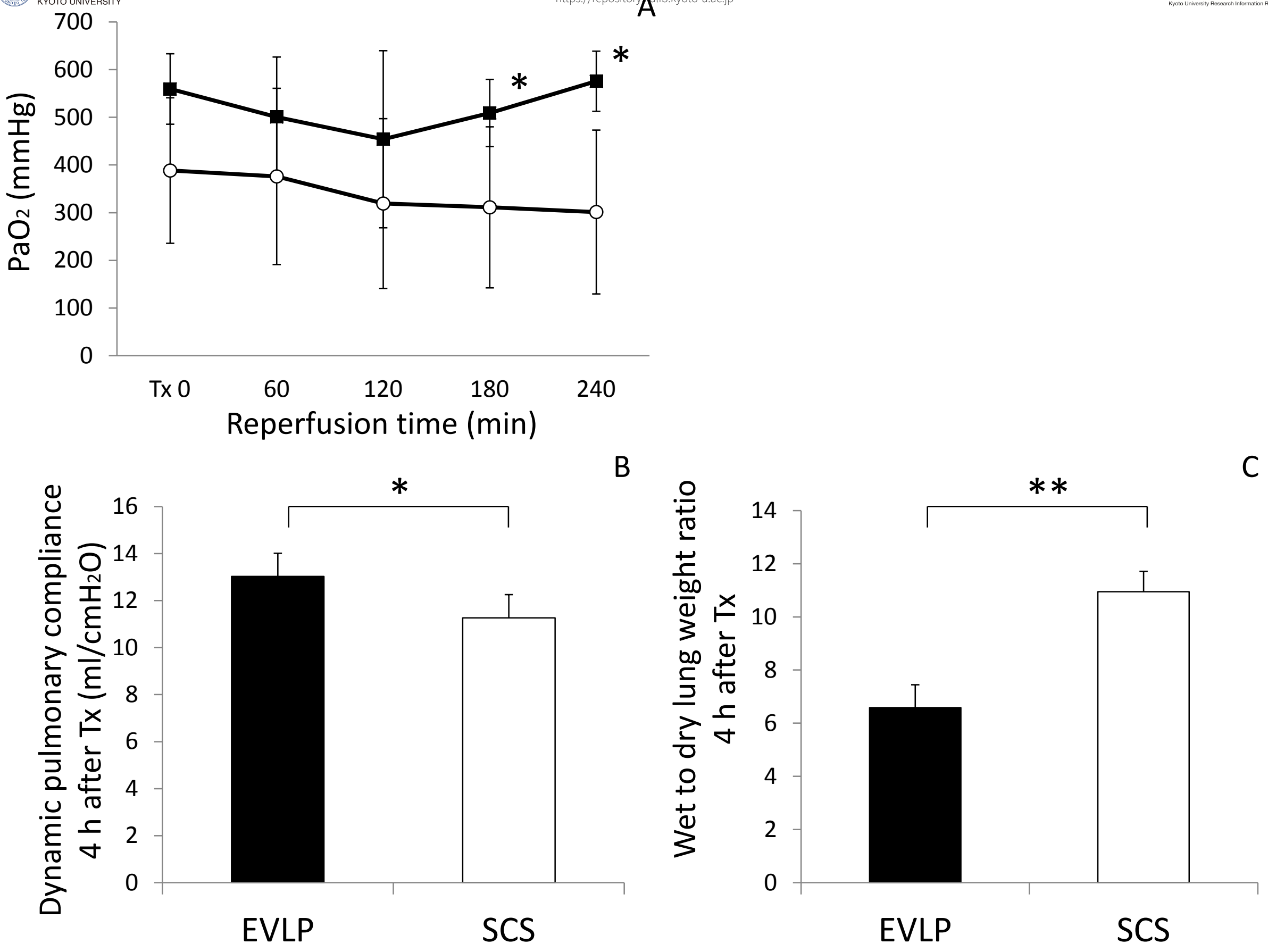

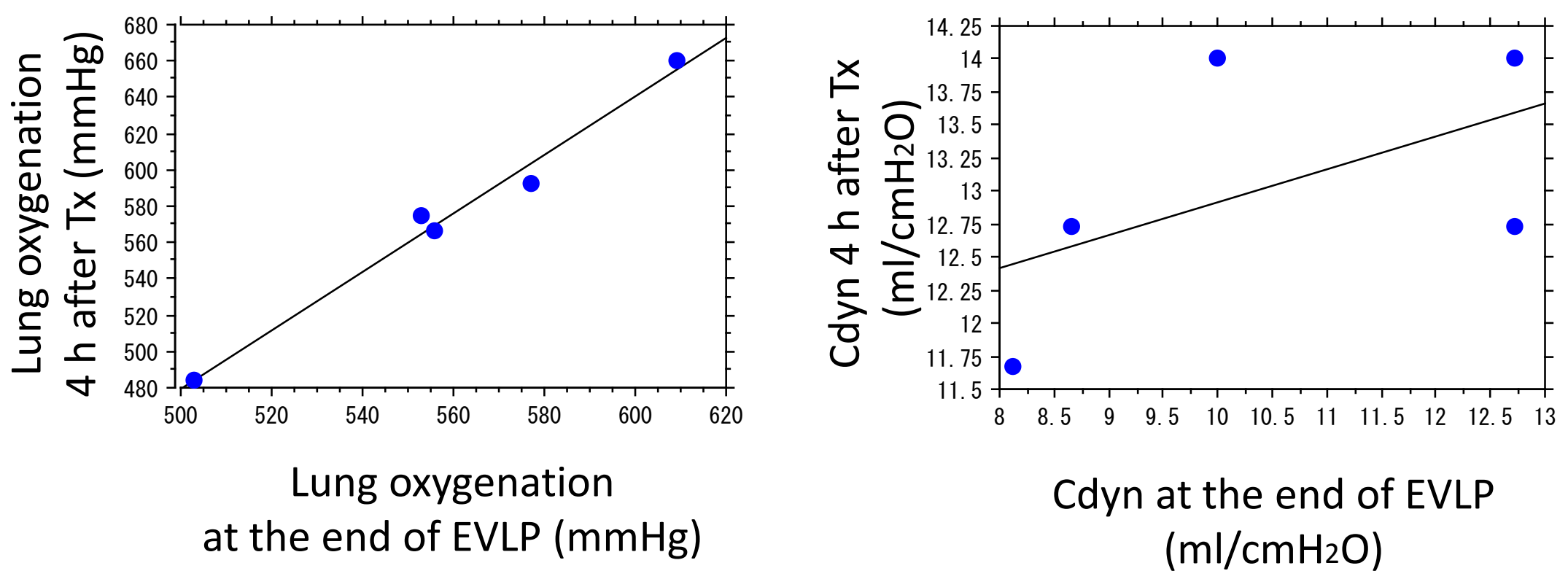


\section{(3.). 京都大学}
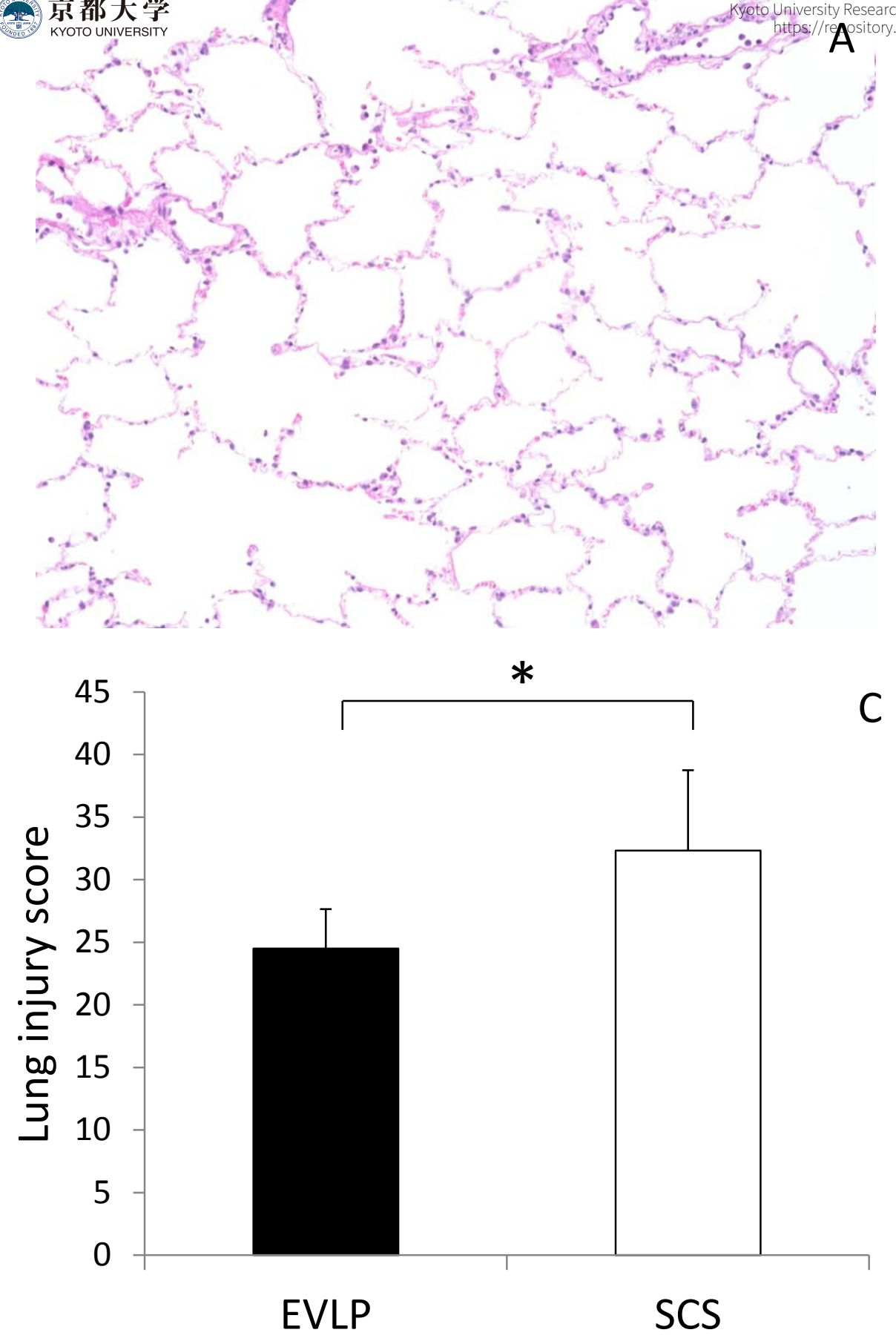

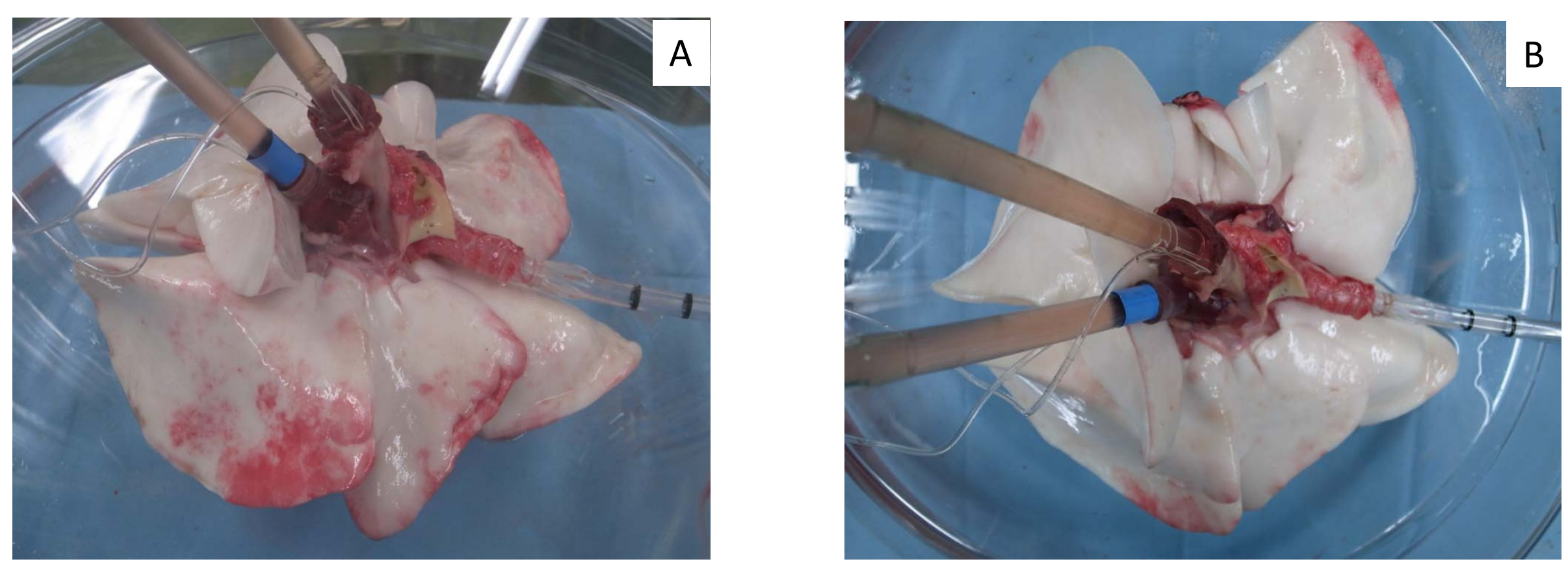


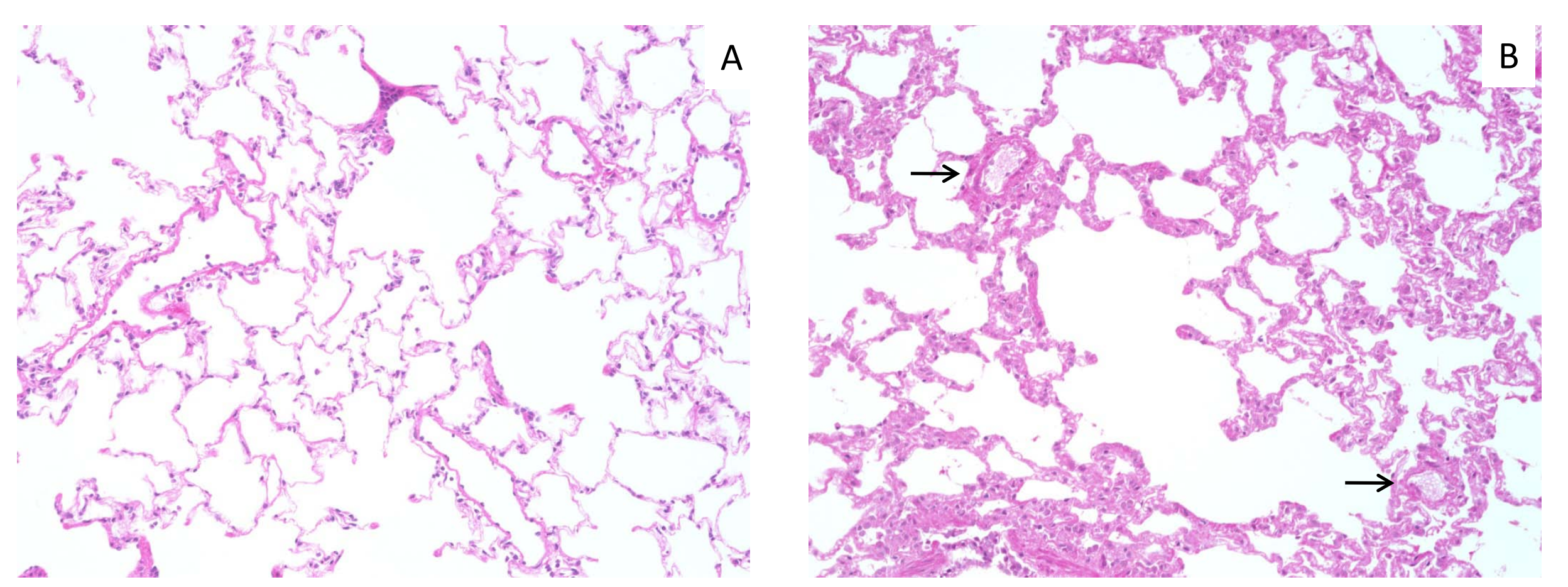




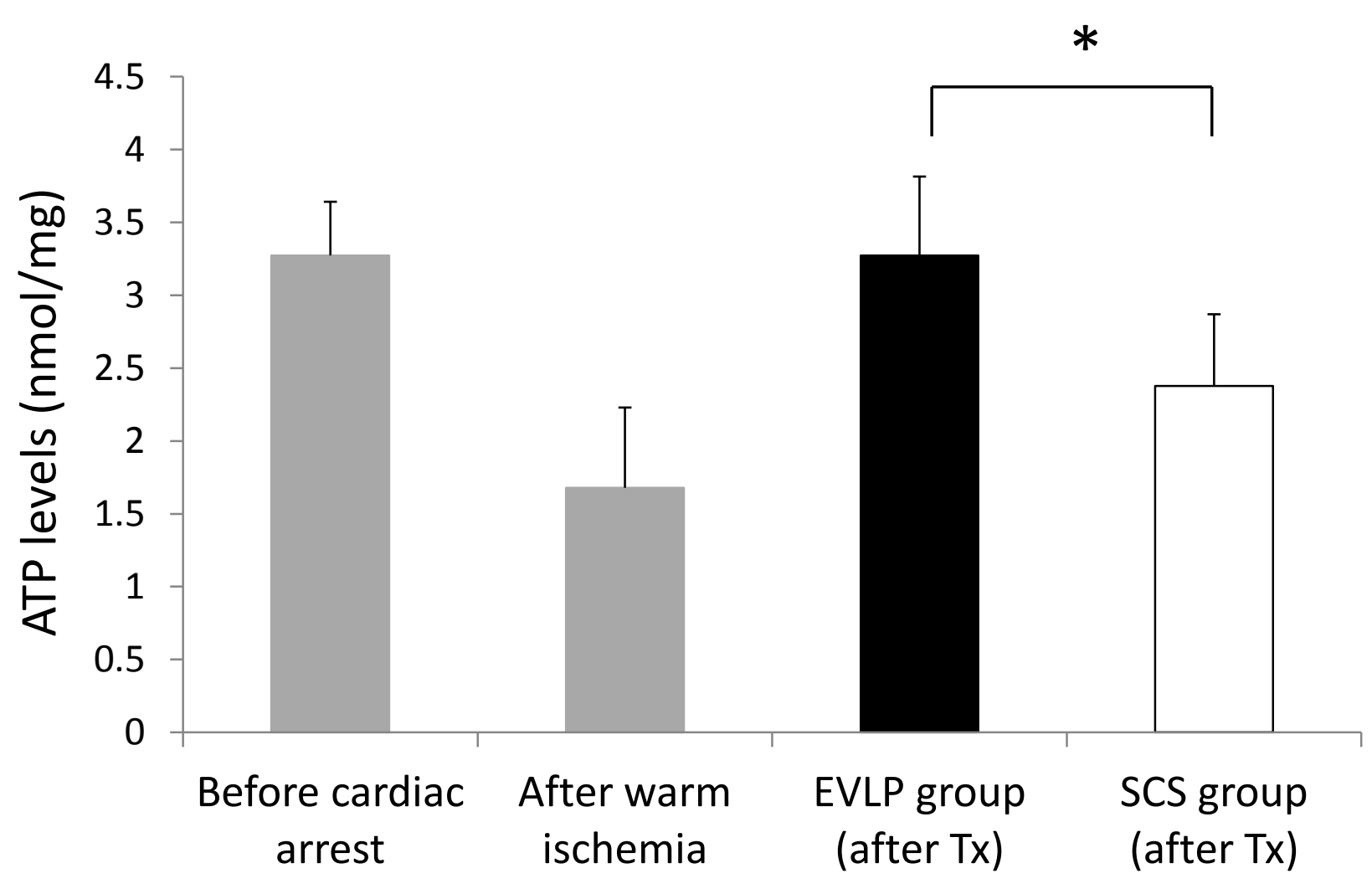

